\title{
Developing Trainee Translators' Strategic Subcompetence Through Metacognitive Questionnaires
}

\author{
Francesc Fernández et Patrick Zabalbeascoa
}

Volume 57, numéro 3, septembre 2012

URI : id.erudit.org/iderudit/ 1017089ar

DOI : 10.7202/1017089ar

Aller au sommaire du numéro

Éditeur(s)

Les Presses de l'Université de Montréal

ISSN 0026-0452 (imprimé)

1492-1421 (numérique)

Découvrir la revue

Citer cet article

Fernández, F. \& Zabalbeascoa, P. (2012). Developing Trainee Translators' Strategic Subcompetence Through Metacognitive Questionnaires. Meta, 57(3), 740-762. doi:10.7202/1017089ar
Résumé de l'article

Le présent article expose une étude de cas réalisée dans un cours de traduction générale (allemand-espagnol) structuré en deux parties. Il est le résultat d'une intervention pédagogique visant à aider les étudiants de première année à développer leur sous-compétence stratégique à l'aide de questionnaires métacognitifs. L'étude est axée sur une fonction précise de cette sous-compétence : l'évaluation de leur processus de traduction. Cette évaluation a été réalisée à l'aide de questionnaires postérieurs à la traduction destinés à faire réfléchir les étudiants sur certains aspects de leur processus de traduction dont les plus pertinents étaient l'identification des problèmes et la justification des solutions. Ces deux aspects ont fait l'objet d'une question double visant à aider les étudiants à identifier les problèmes de traduction bien résolus et à justifier leur solution. Comme le révèle l'analyse des réponses obtenues, les étudiants ont identifié le plus fréquemment les problèmes d'une certaine pertinence stratégique portant sur des conventions générales de style et des expressions caractéristiques des différents genres textuels. Les solutions à ces problèmes ont été aussi les plus fréquemment justifiées et les références aux stratégies de traduction appliquées avec succès ont augmenté d'une partie du cours à l'autre, ce qui témoigne du développement progressif de la sous-compétence stratégique.
Tous droits réservés ( Les Presses de l’Université de Montréal, 2013
Ce document est protégé par la loi sur le droit d'auteur. L'utilisation des services d'Érudit (y compris la reproduction) est assujettie à sa politique d'utilisation que vous pouvez consulter en ligne. [https://apropos.erudit.org/fr/usagers/politiquedutilisation/] 


\title{
Developing Trainee Translators' Strategic Subcompetence Through Metacognitive Questionnaires
}

\author{
FRANCESC FERNÁNDEZ* \\ Universitat Pompeu Fabra, Barcelona, Spain \\ francesc.fernandez@upf.edu \\ PATRICK ZABALBEA SCOA \\ Universitat Pompeu Fabra, Barcelona, Spain \\ patrick.zabalbeascoa@upf.edu
}

\section{RÉSUMÉ}

Le présent article expose une étude de cas réalisée dans un cours de traduction générale (allemand-espagnol) structuré en deux parties. Il est le résultat d'une intervention pédagogique visant à aider les étudiants de première année à développer leur sous-compétence stratégique à l'aide de questionnaires métacognitifs. L'étude est axée sur une fonction précise de cette sous-compétence: l'évaluation de leur processus de traduction. Cette évaluation a été réalisée à l'aide de questionnaires postérieurs à la traduction destinés à faire réfléchir les étudiants sur certains aspects de leur processus de traduction dont les plus pertinents étaient l'identification des problèmes et la justification des solutions. Ces deux aspects ont fait l'objet d'une question double visant à aider les étudiants à identifier les problèmes de traduction bien résolus et à justifier leur solution. Comme le révèle l'analyse des réponses obtenues, les étudiants ont identifié le plus fréquemment les problèmes d'une certaine pertinence stratégique portant sur des conventions générales de style et des expressions caractéristiques des différents genres textuels. Les solutions à ces problèmes ont été aussi les plus fréquemment justifiées et les références aux stratégies de traduction appliquées avec succès ont augmenté d'une partie du cours à l'autre, ce qui témoigne du développement progressif de la sous-compétence stratégique.

\section{ABSTRACT}

This paper presents a case study carried out in a two-part German-Spanish general translation course. It results from a pedagogical intervention aimed at helping first-year translation students to develop their strategic subcompetence through metacognitive questionnaires. It focuses on a single function of this subcompetence, the evaluation of trainees' translating, which was carried out by using post-translation metacognitive questionnaires. These were meant for trainees to reflect on certain aspects of their translating. The most relevant ones were the identification of translation problems and the justification of their solutions. Both aspects were addressed by a twofold question aimed at helping students to identify adequately-solved problems and to justify their solutions. An analysis of students' answers to this question reveals that the most frequently identified items were strategically relevant problems to do with general conventions of style and genre-specific expressions. Solutions to these problems were also the most frequently justified, and references to successfully applied translation strategies increased from one part of the course to the other as a trace of gradually developing strategic subcompetence.

\section{MOTS-CLÉS/KEYWORDS}

sous-compétence stratégique, évaluation, questionnaires métacognitifs, problèmes, stratégies

strategic subcompetence, evaluation, metacognitive questionnaires, problems, strategies 


\section{Introduction}

This paper is meant as a contribution to research into trainees' metacognitive processes within a "functionalist, cognitive translatology" (Muñoz 2010). We present a longitudinal study of the development of trainees' strategic subcompetence (translator training research group PACTE, 2008) as a component of translation competence, through metacognitive questionnaires.

There are certainly empirical studies on self-reflections of translator trainees such as Scott-Tennent and González Davies' (2008) and Hubscher-Davidson's (2008). On the other hand, the use of metacognitive questionnaires enabling trainees to verbalise their reflections on their translating, is a largely unexplored research field with a much smaller literature, although it does include a case study by Fernández (2008). He suggests that metacognitive questionnaires help trainees to become aware of the strategies behind their solutions.

Drawing on Fernández (2008), the case study presented in this paper results from a pedagogical intervention involving the use of post-translation questionnaires. They were aimed at helping Spanish students in a German-Spanish translation course to evaluate certain aspects of their translation process. This kind of evaluating is understood as a function of their strategic subcompetence.

The present study focuses on two aspects of evaluating: identifying translation problems and justifying their solutions. The results of our study suggest that posttranslation questionnaires help trainees to identify translation problems that are strategically relevant, and also helps them to increase the quality of their solutions by making them more and more aware of various translation strategies.

This proves the efficacy of metacognitively-oriented translator training aimed at promoting students' strategic awareness. This awareness is inherent to the development of their strategic subcompetence and defines how this subcompetence can be understood in relation to trainees, starting from PACTE's definition. Our concept of strategic subcompetence for trainees is presented in the conceptual framework of the study, together with its other main concepts: metacognition, socio-constructivism in translator training and metacognitive questionnaires.

\section{Conceptual framework}

\subsection{Strategic subcompetence for trainees as a result of considering PACTE's definition in terms of student awareness}

According to PACTE (2008: 106), translation competence is the expert knowledge system which is needed to translate and which is mainly procedural rather than declarative. It is made up of several interrelated subcompetences, such as the bilingual, extra-linguistic, instrumental and strategic subcompetences.

For PACTE, the latter is the most relevant of all given that "it creates links between the different subcompetences, as it controls the translation process" (PACTE 2008: 107). It is "procedural knowledge to guarantee the efficiency of the translation process" (PACTE 2008: 106) and comprises the following functions:

$[\ldots]$ to plan the process and carry out the translation project [...], to evaluate the process and the partial results obtained in relation to the final purpose, to activate the 
various subcompetences and compensate for any shortcomings and to identify translation problems and apply procedures to solve them. (PACTE 2008: 107)

This definition, conceived in terms of professional translating, is the departing point for our concept of strategic subcompetence for trainees, to be referred to henceforth as strategic subcompetence for the sake of brevity. It applies to teaching in early stages of translator training and involves the functions which we perceive to be most relevant for the development of strategic awareness. These functions are the result of reconsidering the ones established by PACTE's definition, and introducing new functions as required to promote such awareness.

For us, strategic subcompetence has four functions: planning, monitoring, selfevaluating, and activating the various subcompetences. The first three functions are successive stages of the trainees' metacognitive reflection on their translating, which enable them to verbalise certain aspects of this reflection. Two of them are: identifying translation problems, and justifying their solutions by referring to successful strategies.

We consider these two aspects to be additional functions of strategic subcompetence. Both of them are closely, though not exclusively, related to the trainees' evaluation of certain aspects of their translation process. They can be regarded as particularly relevant from a strategic perspective, in that both raise students' awareness of the decision-making process inherent to translating, a process that they may not always be sufficiently aware of.

Their awareness is raised by the explicit verbalising nature of the function that involves justifying their solutions for problems they identified by referring to successful strategies. By "strategy" we understand any conscious action intended to enhance a translator's performance for a given task, especially in terms of efficiency and effectiveness, and resulting in a solution which may be labelled according to its solution-type (Zabalbeascoa 2000: 120).

We use "strategy" instead of "procedure" as we find this to be more coherent with raising student strategic awareness. "Procedure" appears recurrently in the literature (as favoured by authors such as Newmark 1981) with the unstated meaning of solution type, which it is not, since procedure is a prescriptive concept, and solution type is intended to operate within descriptive translation studies. "Procedure" also seems to encapsulate a mechanical process involving systemic differences between languages, whereby a translator does not need to think strategically.

\subsection{The development of strategic subcompetence in a socio-constructivist learning environment through metacognitive questionnaires}

Strategic subcompetence is developed within a community of apprentices, whereby they inductively acquire socially co-constructed knowledge, by using the scaffolding provided not only by the teacher, but also by their peers. By "scaffolding" we understand the help "which will enable a learner to accomplish a task which he would not have been quite able to manage on his own" (Kiraly 2000: 46).

Trainees "collaboratively participate in the authentic activities of professional translators" (Kiraly 2003: 28). In so doing, they acquire socially-shared expertise following a typical three-stage process. According to Anderson (1990: 258-260) this starts when novices develop a declarative knowledge of the skill (cognitive stage). 
Learners can then recognize and address deficits (associative stage). Finally, these actions become increasingly automated, as a more procedural knowledge emerges (autonomous stage).

The process leading trainees to expertise through the development of their strategic subcompetence can be favoured through metacognitive questionnaires (MQs). Adapting Esteve and Arumí's (2006: 164) definition of translator training, we consider them to be mediation instruments that include a series of more or less openended questions that mostly revolve around strategic subcompetence and that can raise their strategic awareness, thereby leading them to incipient expertise.

Through these questions the process of learning how to translate strategically is broken down into more easily manageable chunks. Students deal with them by writing down their answers to sort out their ideas and improve their reasoning. MQs can be used by students to plan, monitor or evaluate their translating, as well as to assess their own learning.

Following Arumí Ribas (2009: 160), we consider that MQs have two principal aims for the teacher: to gradually transfer the control and awareness of educational activities to the trainees and to promote in them intermental dialogue (in social exchange with others) and intramental dialogue (in their own minds), as established by Vygotsky (1978: 42).

The first aim involves fully incorporating MQs in task sequences, so as to allow for reflective learning in a process leading trainees towards cognitive emancipation (by helping them to develop metacognitive strategies for learning how to learn) and, eventually, to increased self-regulated learning. Hence the possible benefit for students of being presented with relevant challenges and given appropriate feedback from the teacher according to their answers to the MQs.

The second aim involves leading trainees to justify their strong and/or weak points through a dialogue originally addressed to the teacher, but pointing back to themselves and including also peers and other agents in a process of knowledge coconstruction. Given the fact that metacognitive reflection includes motivational and socio-emotional processes (Veenman, Van Hout-Wolters et al. 2006: 3-4), trainees should be encouraged to work on MQs in pairs or groups and benefit from peerscaffolding of knowledge.

\section{The study}

\subsection{Setting}

The study was conducted in a general German-Spanish translation course at the Universitat Pompeu Fabra, Barcelona, in the academic year 2007-2008. The course was made up of two parts, each one lasting ten weeks and consisting of three modules. The course included two weekly face-to-face sessions in workshop format, with an additional two hours' autonomous work outside the classroom.

The course was addressed to first-year students with no previous translator instruction and was regularly attended by 15 students (of 20 enrolled). Their level of German was rather heterogeneous, lying, as a rule, slightly below the level of the texts that the students were confronted with, which was A2/B1 (Common European Framework of Reference for Languages). 
One of the researchers was also the course teacher, so he was directly immersed in the reality of the group. The other researcher, himself also a translation teacher, kept the necessary distance from this reality, having access only to the collected data. Thus, he induced a monitoring process exposing the research activity to continual questioning and reevaluation.

\subsection{Pedagogical intervention}

The research was the result of a pedagogical intervention aimed at promoting both strategic subcompetence, represented by the planning and evaluating of the trainees' translating, and their competence to evaluate their learning process. This intervention involved the sequenced use of three types of MQs: pre-translation, posttranslation and end-module (see appendix).

Pre-translation MQs were given to students before each translation assignment and worked on even before the source text was shown. They were conceived to help students to plan their translating on the basis of the brief provided by the teacher. Questions targeted pragmatic features of the source text and the prospective target text, as well as foreseeable translation problems and how they might be solved. The questions were answered orally in class, with the teacher providing the necessary scaffolding. This included additional information, to be read after class, on the most significant problems and their possible solutions, following the functionalist approach (Nord 2005 and 2010).

Post-translation MQs, presented after each translation, were aimed at helping students to evaluate their translating. The questions were primarily focused on how students had proceeded in translating a text, as well as on translation problems and justifying their solutions. The questions were answered by the students in writing out of class, individually or in groups, after each translation assignment, but before students had submitted it to the teacher for correction. The teacher commented on the post-translation MQs also in writing, before handing them back along with the corrected translations, which were then discussed in class.

End-module MQs were aimed at helping students to evaluate their learning at the end of each three-week module. They included questions on the usefulness of these two types of questionnaires and on how they might be improved for future editions. End-module MQs were answered only after all of the pre-translation MQs in the module had been worked on and after all the translations in the module had been submitted for correction along with their corresponding post-translation MQs. End-module MQs were answered in writing by the students and commented on likewise by the teacher before they were handed back.

\subsection{Data selection and collection}

The study deals only with post-translation MQs for two reasons. Their questions applied to strategic subcompetence, unlike the questions in the end-module MQs, and their answers were not teacher-mediated, unlike the answers to the pre-translation MQs. More specifically, the study focuses on the post-translation MQs used in the second module of each of the two parts of the course, to be referred to henceforth as module 2 and module 5. 
One reason for this is that in these two modules post-translation MQs were more frequently used than in any other module, as the number of texts that they applied to was also higher. Students translated three short texts in module 2 and two in module 5, thereby answering an equal number of post-translation MQs. The five texts translated in modules 2 and 5 were the registration conditions of a language course (text 1), the description of the school organising the course (text 2), a piece from a short autobiographical story (text 3), a piece from a text on German recent history (text 4), and a piece from the script of the German film "The Life of Others" (text 5). Another reason for dealing only with post-translation MQs in modules 2 and 5 is that they lay sufficiently apart from each other to make it possible to do a longitudinal study on the development of strategic subcompetence from one part of the course to the other.

The development of this subcompetence is considered only in relation to question 3 in the post-translation MQs for these two modules (appendix 5.2), referred to below as "item 3." It is a twofold question, "what translation problems do you think you have adequately solved and why?" The "what" part of the question pursues the identification of translation problems adequately solved, while the "why" part is intended to get students to verbalise their justifications of the solution for these problems, so that its answers are bound to represent traces of successfully applied strategies. Thus, item 3 targeted the two most relevant functions related to the evaluation of students' translating. Unlike all other items in the post-translation MQs, question 3 did not change from module 2 to module 5 . The analysis of its comparable answers for both modules makes it possible to correlate data from the initial and the final phase of the pedagogical intervention, which coincided with the onset of module 2 and the end of module 5 .

The data collected correspond to trainees' answers to item 3 in the 53 posttranslation MQs submitted in module 2 (34) and in module 5 (19). The number of post-translation MQs for module 2 was higher than for module 5, because in module 5 fewer texts were translated (text 4 took up two weeks' class time) and more posttranslation MQs were done in groups rather than individually, although this had already been possible from the beginning of module 2, which was also the case for translating the texts in groups.

\subsection{Data analysis}

We analysed the data by dealing separately with the students' answers to the "what" and "why" parts of item 3. Two different categories arose: types of problems identified as adequately solved and types of justifications for their solutions. They were arrived at by first segmenting each student's answer into as many parts as different problems and justifications could be made out by means of a thematic analysis. After that, we grouped thematically related items into categories or types.

We relied on identifiable key-words whenever possible; otherwise context-sensitive discourse analysis was needed to interpret the trainees' answers. We recursively matched trainees' answers with the emerging problem-types and types of justifications. In doing so, we followed a process of abstraction and generalization "partly based on participants perspectives and partly based on our own interpretation" (Creswell 2001: 20). 
Finally, we labelled the common core of the trainees' answers in the meta-language used in class, relating the emerging problem- and justification-types with the instruction that they resulted from. This can be illustrated by the problem- and justification-types "general style conventions" and "using the conventional equivalent." The labels actually condense the essence of such answers samples as "Sentences in nominal style, because I've always taken great care in making them sound natural in Spanish, even if this meant changing the German structure."

\subsection{Research paradigm and research questions}

The research paradigm for this study is that of qualitative research, which aims to study "things in their natural settings, attempting to make sense of or interpret phenomena in terms of the meanings people bring to them" (Denziln and Lincoln 1994: 2). Thus, "the researcher is an instrument of data collection who gathers words [...], analyses them inductively [...] and describes a process" (Creswell 2001: 14). In so doing, s/he does not necessarily exclude the quantification of data. For this reason, we use for our research the more inclusive term "interpretive," following Arumí Ribas (2006: 180).

Within our interpretive research we have adopted an ethnographic approach in carrying out a case study. An ethnographic approach is aimed at describing and interpreting a cultural or social group or system (Creswell 2001: 58) and it represents the natural methodology for interpreting educational reality. A case study is an exploration of a system bound by time and place through detailed data collection (Creswell 2001: 61). In the present study, this bound system refers to a group of trainees taking part in the translation course described above.

As for the validity of the results of our study, they can be transferred to situations with similar parameters, given that the constructs and premises underlying the research, as well as its context and the roles of the researchers and participants are sufficiently accounted for. The results can also prove intersubjectively plausible, insofar as they were obtained by triangulation. In our case, this method from the Social Sciences used in process-oriented research in translation (Alves and Gonçalves 2003: 5) involved the collaboration of two researchers in the analysis (investigator triangulation).

In accordance with its research methodology, the present study is guided by two closely related research questions:

1) What was the effect of using post-translation MQs in modules 2 and 5 on the trainees' strategic subcompetence as applied to the function of evaluating their translating, as illustrated by item 3 ?

2) Was there any significant progress in the evaluation of their translating, as reflected in the answers given to that item, as the pedagogical intervention progressed?

These two research questions will be dealt with in the discussion of the results yielded by the analysis (cf. 3.6.) before being answered in the conclusions (cf. 3.7).

\subsection{Results and discussion}

We present the results of the study by dealing successively with two parameters related to the categories arising from the data analysis. These parameters are the identification frequency (IF) for problem-types (PTs) and the justification frequency 
for their solutions (JF). JF will be considered first without distinguishing among justification-types and then by distinguishing them. In considering both types of frequencies we will focus on their relevance and on their evolution in the course of the pedagogical intervention. When featured in tables (Tables 1, 2 and 3), data corresponding to the texts in module 2 will appear highlighted in light grey and data corresponding to the texts in module 5 in dark grey. In turn, data corresponding to all texts taken as a whole will be featured in white lettering.

\subsubsection{Identification frequency for problem-types}

The analysis of students' answers to the "why" part of item 3 resulted in 75 occurrences of problems identified as adequately solved over five different assignments. 12 problem-types (PT1-PT12) emerged, which are presented in Table 1 by frequency. If read by rows, the occurrences apply to the IF for each problem-type in each text (T1-T5) and for all the texts taken as a whole (TOTAL A). When read by columns and added up (TOTAL B), the occurrences apply to the IF of all problem-types for each text (T1-T5).

TABLE 1

Identification frequency for problem-types considered by texts

\begin{tabular}{|l|c|c|c|c|c|c|}
\hline PROBLEM-TYPES & T1 & T2 & T3 & T4 & T5 & $\begin{array}{c}\text { TOTAL } \\
\text { A }\end{array}$ \\
\hline PT1 General style conventions & 5 & 6 & 4 & 4 & 4 & $\mathbf{2 3}$ \\
\hline PT2 Genre-specific expressions & 3 & 8 & & & 1 & $\mathbf{1 2}$ \\
\hline PT3 Vocabulary & & 1 & 4 & 1 & 5 & $\mathbf{1 1}$ \\
\hline PT4 Cultural references & & & 3 & 3 & 3 & $\mathbf{9}$ \\
\hline PT5 The author's style & & & 6 & & & $\mathbf{6}$ \\
\hline PT6 Syntax & & 2 & & 1 & 1 & $\mathbf{4}$ \\
\hline PT7 Text comprehension & & 1 & 1 & 1 & & $\mathbf{3}$ \\
\hline PT8 “Fulfilling the target-text receiver's expectations” & 1 & 1 & & & & $\mathbf{2}$ \\
\hline PT9 “Adding the grammatical subject in Spanish” & & & 2 & & & $\mathbf{2}$ \\
\hline PT10 “Adding information implicit in the source text” & 1 & & & & & $\mathbf{1}$ \\
\hline PT11 “Avoiding literal translation" & 1 & & & & & $\mathbf{1}$ \\
\hline PT12 “Avoiding lexical repetition in Spanish” & 1 & & & & & $\mathbf{1}$ \\
\hline TOTAL B & $\mathbf{1 2}$ & $\mathbf{1 9}$ & $\mathbf{2 0}$ & $\mathbf{1 0}$ & $\mathbf{1 4}$ & $\mathbf{7 5}$ \\
\hline
\end{tabular}

PT1, general style conventions, is the only problem-type to be found in every text and is the one most frequently identified, with almost one third of all occurrences. General style conventions are primarily related to the textual markers which are characteristic of textual genres with the same general communicative function. Textual markers represent recurrent, narrowly defined phenomena, such as the German nominal style, which give this problem-type a generalizable and conventionalized character.

PT2, genre-specific expressions, appears only in three texts and is half as numerous as PT1, representing almost one sixth of all occurrences. Genre specific expressions refer to the more or less recurrent text segments which are characteristic of a specific textual genre and, thus, share a conventionalized - though less generalizable - character with general style conventions. 
PT3, non conventionalized, still less generalizable problems to do with vocabulary, is the third most numerous problem-type. PT3 is slightly less frequent than PT2, genre-specific expressions, despite being present in four texts. PT4, cultural references, is present in three texts and makes up one eighth of all occurrences. PT4 represents a relatively narrowly defined, generalizable phenomenon and is, thus, related to general style conventions (PT1) and genre-specific expressions (PT2).

The fifth most frequently identified problem-type is PT5, the style of the author in the autobiographical short story, with almost a twelfth of all occurrences. It is a narrowly defined but scarcely generalizable phenomenon, as it appears only in text 3. The next two problem-types, syntax (PT6) and text comprehension (PT7), are found in three texts. Both problem-types share a fairly low identification frequency (four and three occurrences) and a less generalizable character which directly relates them to problems to do with vocabulary and with the author's style.

The remaining five problem-types (PT8-PT12) are verbatim quotes from the students and they actually represent translation strategies, such as "avoiding lexical repetition in Spanish" (PT12). So we present them in quotation marks to distinguish them from problem-types proper. They appear only in texts belonging to module 2 , as the case with the author's style (PT5), and show a very small IF: 2 occurrences for PT8 and PT9 and 1 for PT10, PT11 and PT12, with only one such type being present in more than one text.

\section{FIGURE 1}

Identification frequency for groups of problem-types

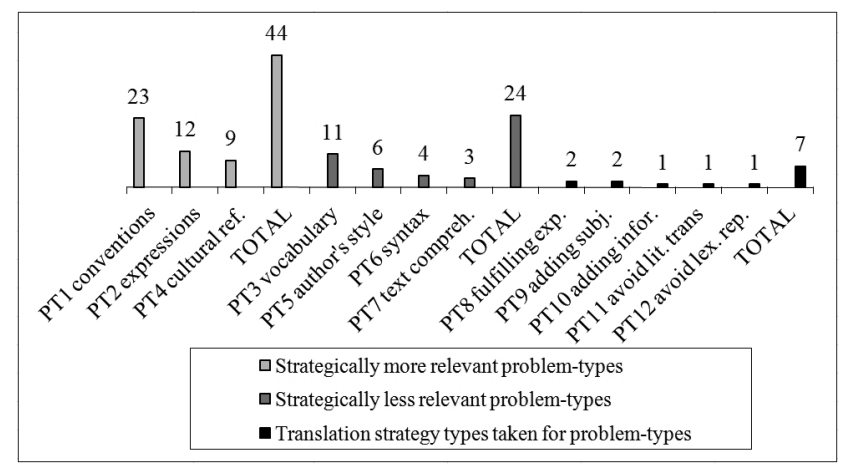

As shown in Figure 1, more generalizable, strategically more relevant problemtypes (PT1, PT2 and PT4) are almost twice as frequent as less generalizable, strategically less relevant problem-types (PT3, PT5, PT6 and PT7). In turn, problem-types referring to translation strategy types (PT8-PT12) are practically three times less frequent than strategically less relevant problem-types and almost six times less frequent than strategically more relevant problem-types. It can thus be stated that post-translation MQs helped students to identify translation problems with a frequency according to their strategic relevance. 
FIGURE 2

Identification frequency by texts

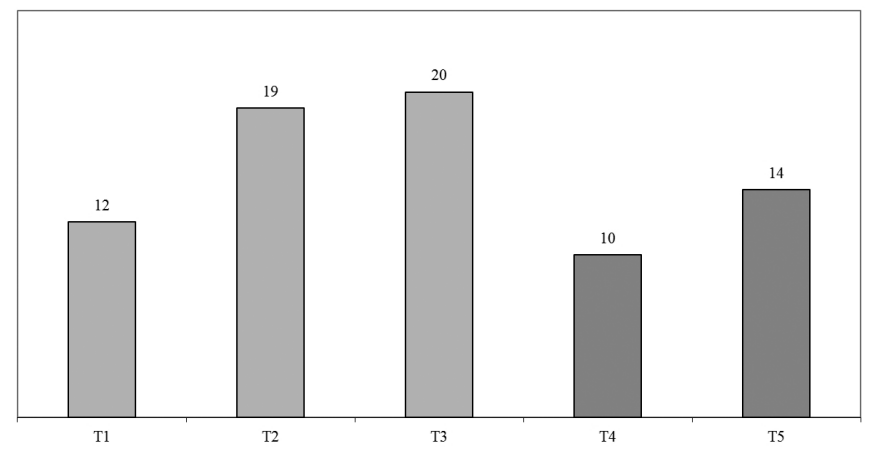

The identification of translation problems, without distinguishing them by groups of types, became more frequent in the course of the pedagogical intervention. As shown in Figure 2, the IF for all problem types by texts presents increased values both from the onset of module 2 (text 1 ) to the end of module 5 (text 5) and within each module.

FIGURE 3

Identification frequency for groups of problem-types considered by texts

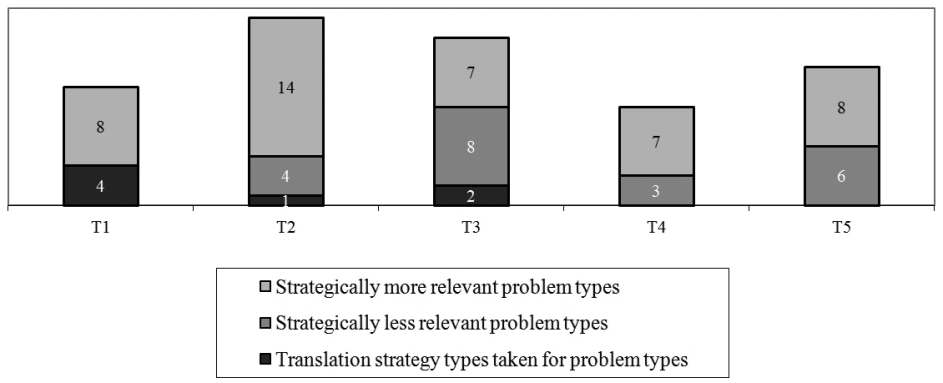

If considered by groups of problem-types and by texts, the IF increased in the course of the pedagogical intervention only in the case of less strategically relevant problem-types. As can be seen in Figure 3, these problem-types were more and more identified both from the onset of module 2 to the end of module 5 and within each module. More strategically relevant problem-types were identified increasingly only over module 5. Problem-types referring to translation strategies were limited to module 2, where they were identified with decreased frequency. They were fully absent from module 5, which points to the students' developing capacity to identify translation problems proper, as they increasingly distinguished these problems from the strategies used for their solution. 
FIGURE 4

Identification frequency for problem-types proper considered by texts

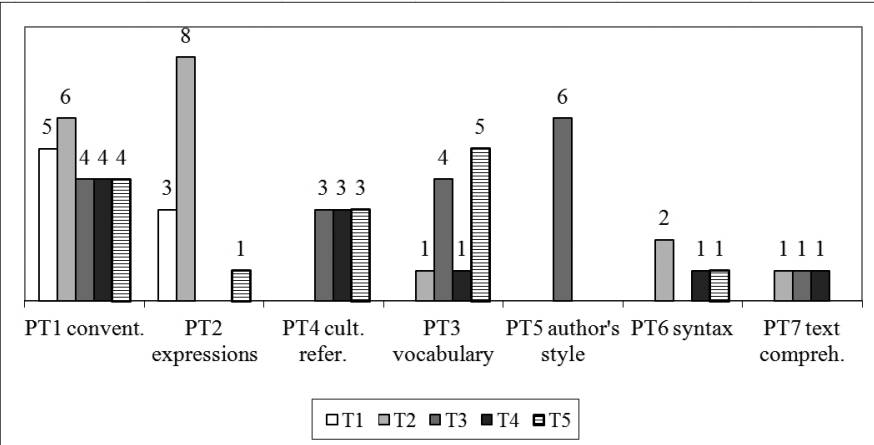

The evolution of the IF for problem-types proper considered by texts restricts progress over the pedagogical intervention to one such problem-type. As shown in Figure 4, only problems to do with vocabulary (PT3) were increasingly identified from the onset of module 2 to the end of module 5, as well as within each of them.

\subsubsection{Justification frequency for solutions to problems}

\subsubsection{Justification frequency considered without distinguishing among justification-types}

The justification frequency for solutions to problems is first considered without distinguishing among justification-types, as shown in Table 2. The 54 occurrences resulting from the students' answers to the "why" part of question 3 and applying to each problem-type for each text are presented following the pattern set for Table 1.

TABLE 2

Justification frequency for problem-types considered by texts

\begin{tabular}{|l|c|c|c|c|c|c|}
\hline PROBLEM-TYPES & T1 & T2 & T3 & T4 & T5 & $\begin{array}{c}\text { TOTAL } \\
\text { A }\end{array}$ \\
\hline PT1 General style conventions & 3 & 5 & 4 & 3 & 4 & $\mathbf{1 9}$ \\
\hline PT2 Genre-specific expressions & 2 & 7 & & & 0 & $\mathbf{9}$ \\
\hline PT3 Vocabulary & & 1 & 1 & 1 & 5 & $\mathbf{8}$ \\
\hline PT4 Cultural references & & & 2 & 3 & 3 & $\mathbf{8}$ \\
\hline PT5 The author's style & & & 4 & & & $\mathbf{4}$ \\
\hline PT6 Syntax & & 1 & & 1 & 1 & $\mathbf{3}$ \\
\hline PT7 Text comprehension & & 0 & 0 & 1 & & $\mathbf{1}$ \\
\hline PT8 “Fulfilling the target-text receiver's expectations” & 0 & 0 & & & & $\mathbf{0}$ \\
\hline PT9 “Adding the grammatical subject in Spanish” & & & 2 & & & $\mathbf{2}$ \\
\hline PT10 “Adding information implicit in the source text” & 0 & & & & & $\mathbf{0}$ \\
\hline PT11 “Avoiding literal translation” & 0 & & & & & $\mathbf{0}$ \\
\hline PT12 “Avoiding lexical repetition in Spanish” & 0 & & & & & $\mathbf{0}$ \\
\hline TOTAL B & $\mathbf{5}$ & $\mathbf{1 4}$ & $\mathbf{1 3}$ & $\mathbf{9}$ & $\mathbf{1 3}$ & $\mathbf{5 4}$ \\
\hline
\end{tabular}


The number of 54 occurrences for justifications lies below that of occurrences for problems. This means that not all problems identified were accounted for. The frequency order in which the solutions for each problem-type are justified almost exactly matches the frequency order in which these problem-types were identified, with two exceptions.

The first exception is vocabulary (PT3). Lying above cultural references (PT4) if considered by its IF, PT3 ranks equal to PT4 if considered by its justification frequency. This being so, the solutions for all three strategically more relevant problemtypes were also the most frequently justified.

The second exception is "adding the grammatical subject in Spanish" (PT9). Although it refers to a translation strategy involving a solution on its own, its "solutions" were more frequently justified than those for text comprehension (PT7), a strategically relevant problem-type whose solutions were not justified at all.

FIGURE 5

Justification frequency for groups of problem-types

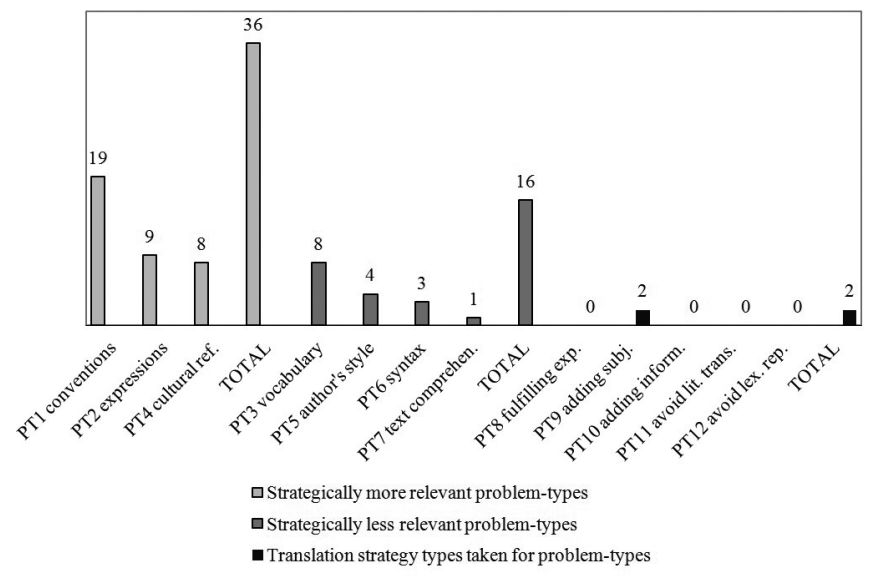

Figure 5 shows that the JF for the solutions of strategically more relevant problem-types is more than twice that of the solutions to less strategically relevant problem-types. In the case of problems referring to translation strategies, the JF for their solutions is $12.5 \%$ of JF for the solutions of strategically less relevant problemtypes and $5.5 \%$ of JF for the solutions of strategically more relevant problem-types.

These differences highlight the fact that, as a rule, the more strategically relevant a problem-type proved, the more frequently its solutions were justified. This would justify the claim that the use of post-translation MQs helped students to justify their solutions for the identified problem-types with a frequency according to the strategic relevance of such problem-types, as was the case with the IF. 
FIGURE 6

Justification frequency by texts

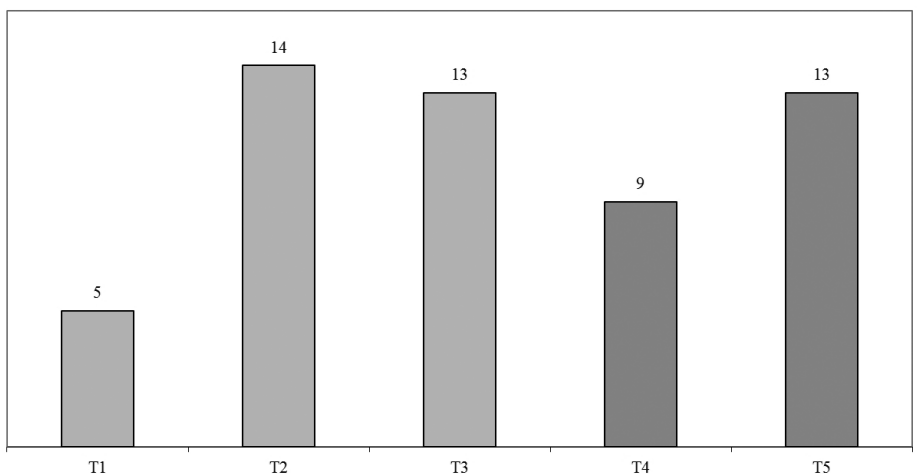

As was also the case with the identification of problem-types, their solutions became more frequently justified in the course of the pedagogical intervention. As represented in Figure 6, the JF for the solutions of all problems taken as a whole shows higher values both from the onset of module 2 to the end of module 5 and within each of these two modules, as was the case with the IF.

It can thus be stated that students justified a growing number of solutions to problems as the pedagogical intervention went on, which fits in with the progressive convergence between IF and JF to be observed from module 2 to module 5 . As shown in Figure 7, students accounted for less than half of the problems identified in text 1, but for almost three quarters of them in text 3. They justified $90 \%$ of the problems in text 4 and even a little more, $93 \%$, in text 5 .

FIGURE 7

Identification and justification frequency by texts

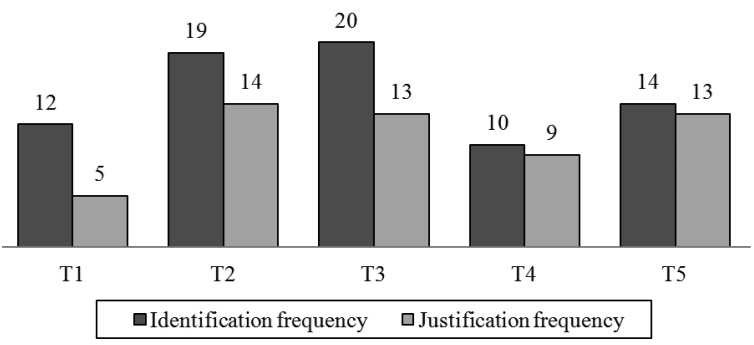

If considered by groups of problem-types and by texts, the JF increased over the pedagogical intervention, as shown in Figure 8, and did so to a greater extent than the IF. Not only strategically less relevant but also strategically more relevant problem-types showed increased values for the justification of their solutions from the onset of module 2 to the end of module 5. In the case of strategically more relevant problem-types, their solutions were also increasingly justified within both modules. Even a problem-type which was actually a strategy taken for a problem presented justified solutions at the end of module 2 , the only one where such problem-types are to be found. 
FIGURE 8

Justification frequency for groups of problem-types considered by texts

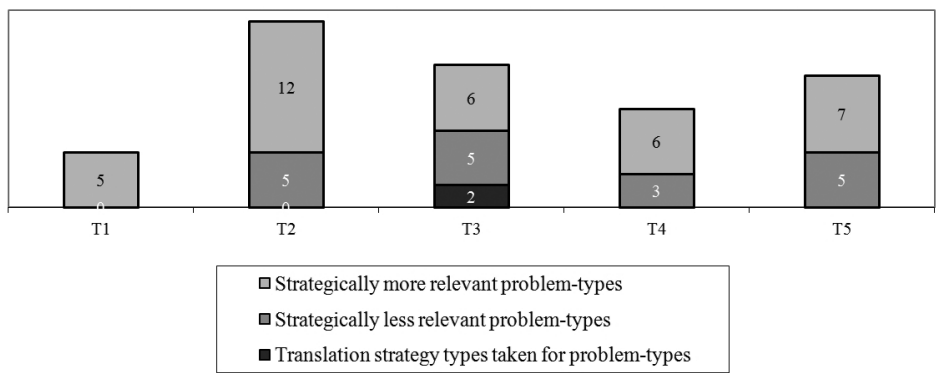

As shown in Figure 9, the JF for the solutions for problem-types proper considered by texts also increased in the course of the pedagogical intervention to a much greater extent than in the case of the IF. Two strategically more relevant problemtypes, general style conventions (PT1) and cultural references (PT4), presented an increased JF for their solutions from module 2 to module 5, as opposed to none in the case of the IF. So did two strategically less relevant problem-types, vocabulary (PT3) and text comprehension (PT7) compared to only one (PT3) in the case of the IF.

FIGURE 9

Justification frequency for problem-types proper considered by texts

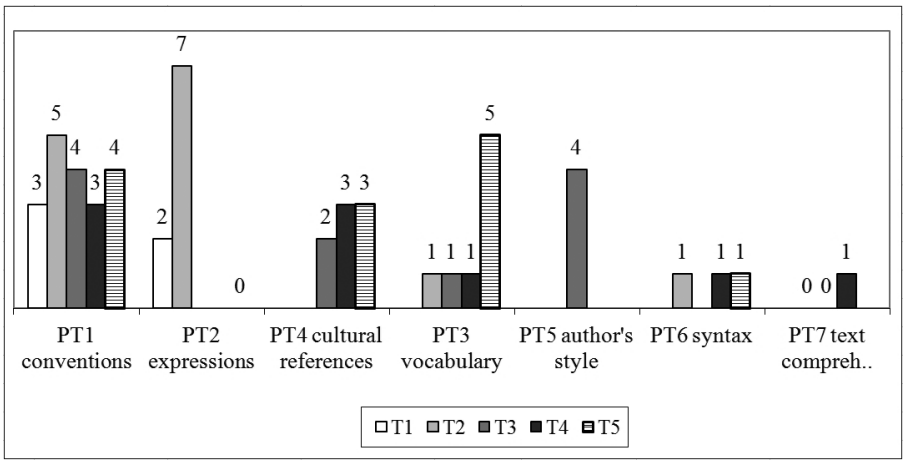

The four strategically relevant problem-types cited above, (PT1, PT3, PT4 and PT7) together with another strategically relevant problem-type, syntax (PT6), add up to ten cases of fully converging justification and identification frequency, as shown in Figure 10. Only two of these cases come from texts in module 2, whilst the remaining eight correspond to texts in module 5 . Such a correlation clearly reveals how much the justification for solutions to problems progressed in the course of the pedagogical intervention. 
FIGURE 10

Identification and justification frequency for problem-types proper considered by texts

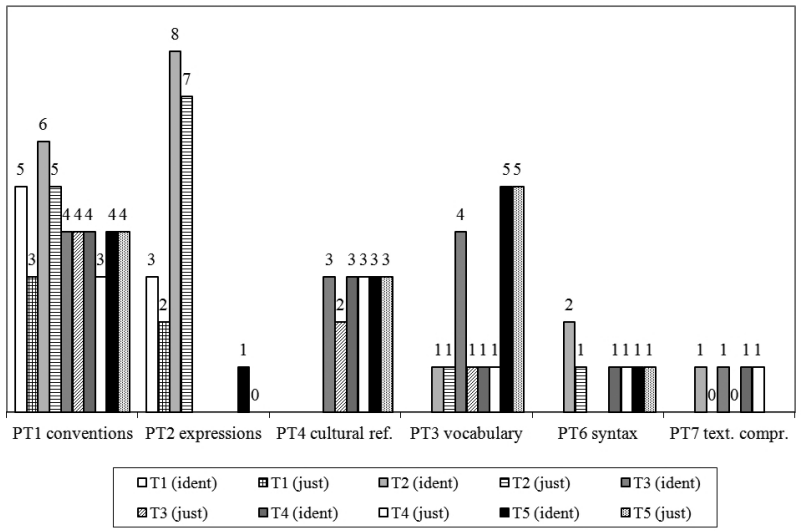

\subsubsection{Justification frequency considered by distinguishing among justification-types}

If we turn to the JF for solutions by distinguishing among justification-types (JTs), 13 such types emerge from the 54 occurrences corresponding to the students' answers to the "why" part of item 3, as shown in Table 3. These occurrences refer to the JF for each JT for each text and are in Tables 1 and 2.

TABLE 3

Justification frequency for justification-types considered by texts

\begin{tabular}{|l|c|c|c|c|c|c|}
\hline JUSTIFICATION-TYPES & T1 & T2 & T3 & T4 & T5 & $\begin{array}{c}\text { TOTAL } \\
\text { A }\end{array}$ \\
\hline JT1 Using the conventional equivalent & 4 & 10 & 2 & 2 & 7 & $\mathbf{2 5}$ \\
\hline JT2 Adding explanations for the target-text receiver & & & 2 & 2 & 1 & $\mathbf{5}$ \\
\hline JT3 Taking the co(n)text into account & & & 1 & 2 & 2 & $\mathbf{5}$ \\
\hline JT4 Maintaining the same style as the source text & & & 3 & & & $\mathbf{3}$ \\
\hline JT5 Thinking of previous solutions for the same problem & & & & 2 & 1 & $\mathbf{3}$ \\
\hline JT6 Conforming to target-language grammar & & 1 & 1 & & & $\mathbf{2}$ \\
\hline JT7 Leaving proper names untranslated & & 1 & & & 1 & $\mathbf{2}$ \\
\hline JT8 Solving grammatical ambiguity in Spanish & & & 2 & & & $\mathbf{2}$ \\
\hline JT9 Using reference sources & & & & 1 & 1 & $\mathbf{2}$ \\
\hline JT10 Following indications given in class & & & 2 & & & $\mathbf{2}$ \\
\hline JT11 Consulting parallel texts & 1 & & & & & $\mathbf{1}$ \\
\hline JT12 Adequately comprehending the source text & & 1 & & & & $\mathbf{1}$ \\
\hline JT13 Avoiding lexical repetition in Spanish & & 1 & & & & $\mathbf{1}$ \\
\hline TOTAL B & $\mathbf{5}$ & $\mathbf{1 4}$ & $\mathbf{1 3}$ & $\mathbf{9}$ & $\mathbf{1 3}$ & $\mathbf{5 4}$ \\
\hline
\end{tabular}

JT1, using the conventional equivalent, is a translation strategy, the only one applying to all five texts and, thus, the most frequent, with almost half of all occurrences. JT2 and JT3, adding explanations for the target-text receiver and taking the co(n)text into account, represent translation strategies, too. They appear in the same 
three texts during the progress of both modules and show the same JF, five occurrences, which represents one fifth of the frequency for JT1

JT4, maintaining the same style as in the source text, is also a translation strategy. It applies only to a single text and its justification frequency is almost the half of JT2 and JT3: three occurrences. With the same number of occurrences as JT4, JT5, thinking of previous solutions for the same problem, appears in two texts. It also differs from JT4, in that it is not a translation strategy, but a metacognitive strategy, as its focus lies on how a solution type was arrived at. This points to metacognitive reflection which, in this case, was related to the trainees' own learning how to learn.

There follow five justification-types, JT6 to JT10, with a very small justification frequency, two occurrences. JT6, JT7, JT8 and JT9, conforming to target-language grammar, leaving proper names untranslated, solving grammatical ambiguity in Spanish and using reference source, represent translation strategies which mostly appear in two texts. JT10, following indications given in class, is a metacognitive strategy, with metacognitive reflection now related to the teacher's recommendations.

The three last justification-types, JT11, JT12 and JT13, consulting parallel texts, adequately comprehending the source text and avoiding lexical repetition in Spanish, correspond to the translation strategies with the lowest justification frequency: one occurrence each. It is worth noting that the last of these justification-types exactly matches the last problem type identified, although both apply to different texts in module 2 .

FIGURE 11

Justification frequency for justification-types considered by groups

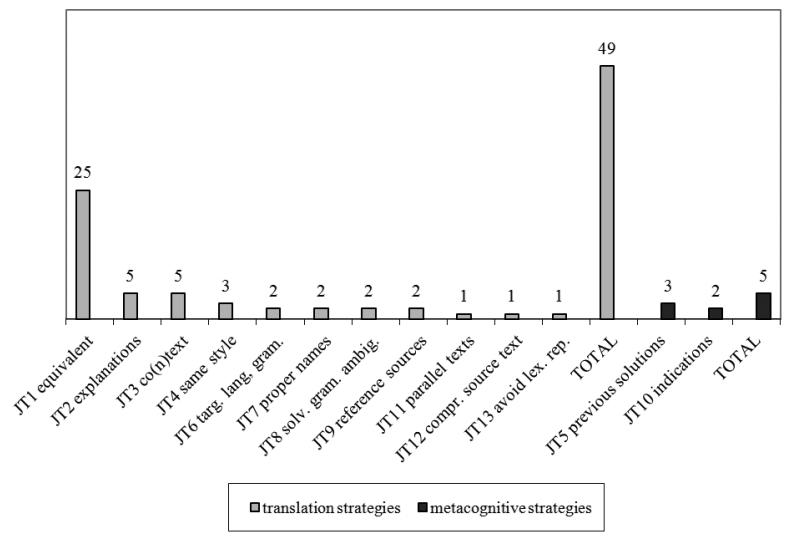

As shown in Figure 11, just over 90\% of occurrences for all justification-types correspond to translation strategies, which reveals their salient relevance. Metacognitive strategies present a much smaller JF, almost $10 \%$. They can, though, be regarded as relevant, in that trainees activated them for retrieving appropriate solution types, thereby increasing their strategic awareness, as they learned how to learn. The use of post-translation MQs helped them, in this way, to justify their solutions for the problem-types previously identified, by leading them to refer to successfully applied relevant strategies. 
FIGURE 12

Justification frequency for justification-types present in both modules considered by texts

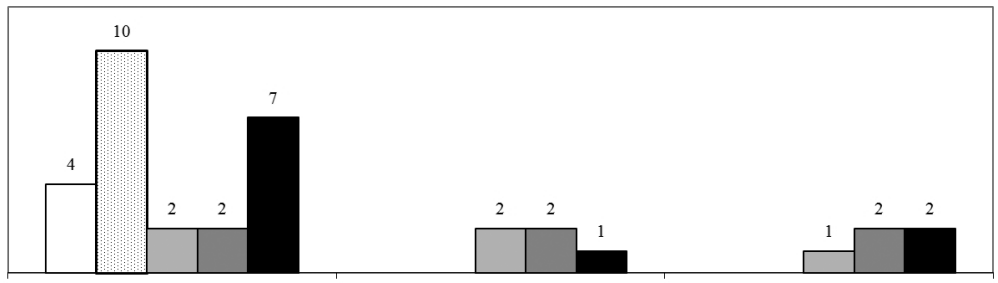

JT1 conventional. equivalents

JT2 explanations for ther target text-receiver

JT3 co(n)text into account

$\square \mathrm{T} 1 \mathrm{\square T} 2 \mathrm{\square T} 3 \mathrm{aT} 4 \mathbf{\mathrm { T }} 5$

Regarding the strategies applied to texts in both modules, the three most frequent ones were referred to more and more over the pedagogical intervention in only two cases, as shown in Figure 12. Of them the most significant one corresponds to the translation strategy "using the conventional equivalent." Its JF presents increasing values both from the onset of module 2 to the end of module 5 and within module 5 , though not within module 2 .

The use of post-translation MQs led trainees to justify their solutions in a clearly progressive manner only in the case of the JT corresponding to the most frequent translation strategy. It also got trainees to refer to an increasing number of JT over the pedagogical intervention in justifying their solutions, as shown in Figure 13.

FIGURE 13

Number of justification-types mentioned for each text

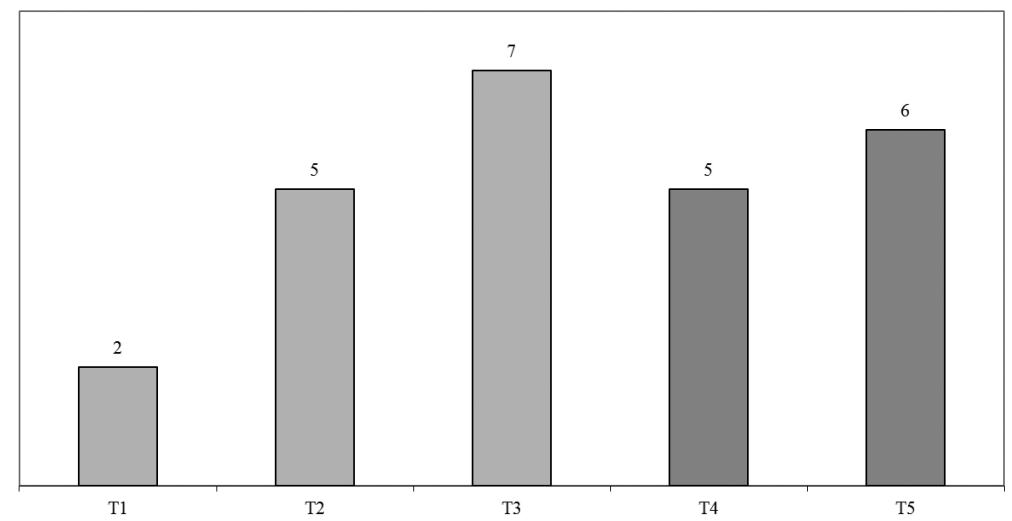

Finally, we will deal with the JF for solutions in relation to the problem-types that they apply to. As shown in Table 4, this frequency is considered both for each JT within each problem-type (TOTAL A, if read by rows) and for each PT (TOTAL $B$, if read by rows). In both cases, it is also established for each text (TOTAL A, if read by columns) and for all taken as a whole (TOTAL B, if read by columns). 
TABLE 4

Justification frequency for justification-types considered by problem-types and texts

\begin{tabular}{|c|c|c|c|c|c|c|c|}
\hline $\begin{array}{l}\text { PROBLEM-TYPES and their } \\
\text { JUSTIFICATION-TYPES }\end{array}$ & $\mathrm{T} 1$ & $\mathrm{~T} 2$ & T3 & $\mathrm{T} 4$ & T5 & $\begin{array}{c}\text { TOTAL } \\
\text { A }\end{array}$ & $\begin{array}{l}\text { TOTAL } \\
\text { B }\end{array}$ \\
\hline PT1 General style conventions & & & & & & & 19 \\
\hline JT1 Using the conventional equivalent & 3 & 5 & 2 & 2 & 3 & 15 & \\
\hline JT3 Taking the co(n)text into account & & & & & 1 & 1 & \\
\hline $\begin{array}{l}\text { JT5 Thinking of previous solutions for the same } \\
\text { problem }\end{array}$ & & & & 1 & & 1 & \\
\hline JT6 Conforming to target-language grammar & & & 1 & & & 1 & \\
\hline JT10 Following indications given in class & & & 1 & & & 1 & \\
\hline PT2 Genre-specific expressions & & & & & & & 9 \\
\hline JT1 Using the conventional equivalent & 1 & 5 & & & & 6 & \\
\hline JT11 Consulting parallel texts & 1 & & & & & 1 & \\
\hline JT12 Adequately comprehending the source text & & 1 & & & & 1 & \\
\hline JT13 Avoiding lexical repetition in Spanish & & 1 & & & & 1 & \\
\hline PT3 Vocabulary & & & & & & & 8 \\
\hline JT1 Using the conventional equivalent & & & & & 4 & 4 & \\
\hline JT3 Taking the co(n)text into account & & & 1 & 1 & & 2 & \\
\hline JT7 Leaving proper names untranslated & & 1 & & & & 1 & \\
\hline JT9 Using reference sources & & & & & 1 & 1 & \\
\hline PT4 Cultural references & & & & & & & 8 \\
\hline $\begin{array}{l}\text { JT2 Adding explanations for the target-text } \\
\text { receiver }\end{array}$ & & & 2 & 2 & 1 & 5 & \\
\hline JT3 Taking the co(n)text into account & & & & & 1 & 1 & \\
\hline JT7 Leaving proper names untranslated & & & & & 1 & 1 & \\
\hline JT9 Using reference sources & & & & 1 & & 1 & \\
\hline PT5 The author's style & & & & & & & 4 \\
\hline JT4 Maintaining the same style as the source text & & & 3 & & & 3 & \\
\hline JT10 Following indications given in class & & & 1 & & & 1 & \\
\hline PT6 Syntax & & & & & & & 3 \\
\hline $\begin{array}{l}\text { JT5 Thinking of previous solutions for the same } \\
\text { problem }\end{array}$ & & & & 1 & 1 & 2 & \\
\hline JT6 Conforming to target-language grammar & & 1 & & & & 1 & \\
\hline PT7 Text comprehension & & & & & & & 1 \\
\hline JT3 Taking the co(n)text into account & & & & 1 & & 1 & \\
\hline PT9 Adding the grammatical subject in Spanish & & & & & & & 2 \\
\hline JT8 Solving grammatical ambiguity in Spanish & & & 2 & & & 2 & \\
\hline $\begin{array}{l}\text { TOTAL A } \\
\text { TOTAL B }\end{array}$ & 5 & 14 & 13 & 9 & 13 & 54 & 54 \\
\hline
\end{tabular}

As can be seen, there is a clear relation between each problem-type (PT) and the most frequent JT for its solution. Such relevance primarily applies to translation strategies, which represent the most frequent JT for the solutions of all problem-types but one. This is syntax (PT6), whose solutions had its most frequently justified solution in a metacognitive strategy.

Solutions for problems to do with general style conventions (PT1) were most frequently justified by referring, understandably, to the use of the conventional 
equivalent (JT1), the most frequent JT. This was the translation strategy most frequently applied to genre-specific expressions (PT2) too, given their conventionalized character. It was also the most frequently justified solution for a strategically less relevant problem-type, vocabulary (PT3), thereby showing its contrasted relevance. It did not present, though, an increased JF over the pedagogical intervention in the case of the only problem-type, PT1, that it applied to in both modules.

Cultural references (PT4) consequently had their most frequently justified solution in "adding explanations for the target-text receiver" (JT2), a translation strategy which did not present increased JFs over the pedagogical intervention.

Solutions for problems concerning the author's style (PT5) and text comprehension (PT8), were most frequently accounted for through relevant translation strategies: maintaining the same style as the source text (JT4) and taking the co(n)text into account (JT3). This relevance applied to the translation strategy, solving grammatical ambiguity in Spanish (JT8), justifying the solutions for the only problem-type representing a translation strategy, "adding the grammatical subject in Spanish" (PT9).

Solutions for problems related to syntax (PT6) were most frequently justified through the metacognitive strategy "thinking of previous solutions for the same problem" (JT5). This was the most frequent of such strategies and also applied to general style conventions (PT1). So did the other metacognitive strategy, following indications given in class (JT10), which also accounted for the solutions of problems to do with the author's style (PT5). In all cases, following indications given in class (JT10) applied to texts in module 2 and thinking of previous solutions for the same problem (JT5) to texts in module 5, thus suggesting a progression from external to internal self-regulation

To sum up, it may be stated that trainees using post-translation MQs justified the solutions for the problem-types by referring primarily to translationally but also to metacognitively relevant strategies. This did not happen, though, with increased JF from the onset to the end of the pedagogical intervention.

\section{Conclusions}

We will now answer the two research questions guiding the present study and consider its main contributions.

Firstly, using post-translation metacognitive questionnaires in modules 2 and 5 promoted the development of the strategic subcompetence of evaluating their translating, more precisely, for identifying translation problems and justifying their solutions. This meant that translation problems were all more frequently identified the more strategically relevant they proved. Their solutions were justified on the same basis. As a rule, the frequency of these justifications also grew and their number eventually became similar to the number of problems identified. Justifying solutions to translation problems involved referring not only to translation strategies but also to metacognitive strategies. Using the conventional equivalent (JT1) and thinking of previous solutions for the same problem (JT5) were, respectively, the most frequent and relevant. The range of both types of strategies became wider the greater the relevance of the problem-type they were used to solve. General style conventions (PT1) and genre-specific expressions (PT2) were the most frequently identified problem-types as well as the ones whose solutions were most frequently justified according to the type of texts chosen and instruction given. 
Secondly, there was significant progress in the students' evaluation of their translating from the onset to the end of the pedagogical intervention. This was the case, to a lesser extent, in identifying translation problems compared to justifying their solutions. The IF presented increasing values over the pedagogical intervention only when considered for all problem-types, as well as for strategically less relevant problem-types. Translation strategies that the students regarded as problems were identified only in the first part of the course and, then, less and less. As for trainees' solutions, their JF for all problem-types grew considerably more than the IF over the pedagogical intervention. Further, the solutions for strategically more and strategically less relevant problem-types were increasingly justified from the onset of the pedagogical intervention to its end. Thus, trainees justified the solution for a growing number of problems identified, while referring to an increased number of JT. Two of them, out of the three translation strategies used in both parts of the course, and notably the conventional equivalent (JT1), were referred to more and more in the course of the pedagogical intervention. Even the two metacognitive strategies deployed were so gradually distributed throughout the course as to allow for a progression from external to internal self-regulation.

We would now like to put forward the three main contributions of the study, which, in our opinion, have relevant implications for metacognitively oriented translator training, promoting strategic awareness through self-regulated learning.

The first contribution is the pedagogical concept of strategic subcompetence for translator trainees. This is made up of three functions, corresponding to successive stages of their metacognitive reflection on their translating: planning, monitoring and evaluating. Closely related to the trainees' evaluating of their translating are two other functions, which are particularly relevant in promoting strategic awareness in students. These are identifying translation problems and, especially, justifying one's solutions to these problems, as this involves trainees referring to successfully applied strategies, thereby becoming aware of their own decisionmaking process.

The second contribution is the finding that trainees refined their identification of translation problems from one part of the course to the other. Only translation problems proper were spotted in the second part of the course, after translation strategies had been taken for such problems in the first. This refining process resulted, thus, in the trainees' appropriating the metatranslational relevant distinction between problems and strategies applying to the solutions of these problems. This may well be considered a trace of incipient expertise pointing to developing strategic subcompetence with regard to trainees' evaluation of their translating and, more precisely, regarding the identification of translation problems.

The third contribution is the finding that trainees justified their solutions for a growing number of translation problems from one part of the course to the other. The solutions for both strategically more and less relevant problem-types were more frequently accounted for in the second part of the course than in the first. This justification process resulted in the trainees' appropriating the metatranslational relevant use of translation strategies, sometimes enhanced by the also increased use of metacognitive strategies. This may be considered a trace of incipient expertise pointing again to developing strategic subcompetence, related now to trainees' self-evaluating by justifying solutions to identified problems. 
Both findings apply to the trainees' growing appropriation of metatranslational knowledge. The relevance of this appropriation process lies in the fact that it developed independently from the teacher's assistance, as it kept constant throughout the course, and regardless of the characteristics of each text, as especially shown by the steady growth of justifications for solutions to problems, irrespectively of the number of identified problems. This suggests the tentative conclusion that the appropriating had its origin in the recurrent use of post-translation metacognitive questionnaires, possibly enhanced by their being more frequently answered in groups in the second part of the course. This hypothesis, though, needs to be confirmed through further research into trainees' evaluation of their translating with metacognitive questionnaires answered also in teamwork.

\section{ACKNOWLEDGMENTS}

The authors would like to thank Joëlle Rey (in memoriam) for the French version of the abstract.

\section{NOTES}

* This article was written as part of the research project A Study of the Tutorial as an Instrument of Orientation in Foreign Language (ETOILE is its Spanish acronym), reference number EDU200801835/EDUC, financed by the Spanish Ministry of Science and Innovation.

\section{REFERENCES}

Alves, Fabio and Gonçalves, José Luiz V. R. (2003): A Relevance Theory approach to inferential processes in translation. In: Alves, Fabio, ed. Triangulating Translation. Amsterdam/ Philadelphia: John Benjamins, 3-24.

Anderson, John R. (1990): Cognitive Psychology and its implications. New York: W.H. Freeman. Arumí Ribas, Marta (2006): Incidència d'una acció pedagògica dirigida a l'autoregulació, Dos estudis de cas a l'aula d'iniciació a l'aprenentatge de la interpretació consecutiva. Doctoral dissertation, unpublished. Barcelona: Universitat Autònoma de Barcelona.

Arumí Ribas, Marta (2009): Nuevos retos en la formación de intérpretes; la integración del componente metacognitivo en el aula. Trans. Revista de traductología. 13:149-162.

Creswell, John W. (2001): Qualitative Inquire and Research Design. Thousand Oaks: Sage.

Denziln, Norman K. and Lincoln, Yvonna S. (1994): Handbook of Qualitative Research. Thousand Oaks: Sage.

Esteve, Olga and Arumí, Marta (2006): Using instruments aimed at self-regulation in the consecutive interpreting classroom: Two case studies. Electronic Journal of Foreign Language Teaching. 3(2):158-189. Visited on 5 March 2012, <http://e-flt.nus.edu.sg/v3n22006/ esteve_arumi.pdf $>$.

Fernández, Francesc (2008): An Example of a Collaborative Translation Project Incorporating Mediation Instruments as a Means of Encouraging Self-Regulation. In: Mike Garant and Larry Walker, eds. Current Trends in Translation Teaching and Learning. Volume II. Helsinki: Publications of the Department of Translation Studies V, 121-151.

Hubscher-Davidson, Severine (2008): A Reflection on Action Research Processes in Translator Training: Project on Group Work in Level 2 Translation Classes. The Interpreter and Translator Trainer. 2(1):75-92.

Kiraly, Donald (2000): A Social Constructivist Approach to Translator Education. Manchester: St. Jerome.

Kiraly, Donald (2003): From Instruction to Collaborative Construction. In: Brian James Braer and Geoffroy S. Сову, eds. Beyond the Ivory Tower: Rethinking Translation Pedagogy. Amsterdam/Philadelphia: John Benjamins, 1-28. 
Munõz Martin, Ricardo (2010): On the paradigms and cognitive translatology. In: Gregory Shreve and Erik Angelone, eds. Translation and Cognition. Amsterdam: John Benjamins, 169-187.

Newmark, Peter (1981): Approaches to Translation. Oxford: Pergamon.

Nord, Christiane (2005): Training functional translators. In: Martha Tennent, ed. Training for the New Millenium. Amsterdam/Philadelphia: John Benjamins.

Nord, Christiane (2010): Functionalist approaches. In: Yves Gambier and Luc Van Doorslaer, eds. Handbook of Translation Studies. Amsterdam/Philadelphia: John Benjamins.

Pacte Group (2008): First Results of a Translation Competence Experiment: 'Knowledge of Translation' and 'Efficacy of the Translation Process.' In: John Kearns, ed. Translator and Interpreter Training. Issues, Methods and Debates. Leeds: Centre for Translation Studies, University of Leeds, 104-126.

Scott-Tennent, Christopher and Gonzalez Davies, María (2008): Effects of Specific Training on the Ability to Deal with Cultural References in Translation. Meta. 53(4):782-797.

Veenman, Marcel, Van Hout-Wolters, Bernadette and Afflerbach, Peter (2006): Metacognition and learning: conceptual and methodological considerations. Metacognition and Learning. 1:3-14.

Vygotsky, Lev S. (1978): Mind in Society: The Development of Higher Psychological Processes. Cambridge: Harvard University Press.

ZabalbeascoA, Patrick (2000): From Techniques of Translation to Types of Solutions. In: Allison Beeby, Doris Ensinger and Marisa Presas, eds. Investigating Translation. Amsterdam/ Philadelphia: John Benjamin Press, 117-127.

\section{APPENDICES}

\section{Pre-translation MQ for text 1}

1 Knowing that the sender of the registration conditions that you are going to translate is the German language school Sprachforum München, who do you think their receivers might be?

2 What might the sender intend from the receiver with these registration conditions?

3 If you were the receiver of the target text, what should it be like to meet your expectations?

4 What kind of contents can you expect to find in registration conditions and in what logical order? Be as precise as possible.

5 If you happen to know them beforehand, please cite some fixed phrases in Spanish that could appear in registration conditions originally written in that language.

6 In your opinion, what will be the most serious problems that you will have to face in translating registration conditions from German into Spanish and how will you solve them?

\section{Post-translation MQ for text 1}

1 Have you learnt anything new about the subject of the source text? If so, what?

2 Have you consulted any information source to get (more) background information on the subject of the source text? If so, which ones?

3 What translation problems do you think you have adequately solved and why?

4 What would you recommend to another peer having to translate this text or an instance of the genre it belongs to?

5 Have you checked your translation for coherence, by reading it again - without looking at the source text - some days after completing it and by making sure that it was comprehensible for another Spanish speaking person?

6 Have you checked your translation for stylistic questions by looking up odd sounding combinations of

a) noun + adjective or prepositional clause

b) verb + noun

that can be found in parallel texts, monolingual dictionaries or electronic corpora? 


\section{End-module MQ for module 2}

1 What have you learnt by collectively answering the questions in the pre-translation questionnaires used in the module?

2 Do you think that you would "automatically" ask yourself in the future any of the questions in the pre-translation questionnaires, even if no such questionnaires needed to be answered? Which ones would they be?

3 What have you learnt by answering the questions in the post-translation questionnaires used in the module?

4 Do you think that you would "automatically" ask yourself in the future any of the questions in the post-translation questionnaires, even if no such questionnaires had to be answered? Which ones?

5 Do you think that certain questions could be omitted from post-translation questionnaires in the future?

6 Looking back, do you think that the post-translation questionnaires have helped you to become aware of translation errors? If so, give please one or two examples. 